\title{
Respiratory Care Year in Review 2010: Part 1. Asthma, COPD, Pulmonary Function Testing, Ventilator-Associated Pneumonia
}

\author{
Bruce K Rubin MD MEngr MBA FAARC, Rajiv Dhand MD FAARC, \\ Gregg L Ruppel MEd RRT RPFT FAARC, Richard D Branson MSc RRT FAARC, \\ and Dean R Hess PhD RRT FAARC
}

\author{
Introduction \\ Asthma \\ Genetics and Epigenetics \\ Exposures \\ Viruses \\ Diet, Obesity and Exercise \\ Exhaled Nitric Oxide \\ Drug Therapy: $\beta$ Agonists, Macrolides, Tiotropium, and Monteleukast \\ Other Studies \\ COPD \\ Childhood Disadvantage Factors and COPD \\ Vitamin D deficiency and COPD \\ $\beta$-Blockers and COPD \\ Corticosteroid Therapy During COPD Exacerbations \\ Oxygen Administration During Pre-hospital Transport of Patients With \\ COPD Exacerbation \\ Prognosis of Patients Admitted to the Hospital for COPD Exacerbation \\ Pulmonary Function Testing \\ Pulmonary Function Testing Methods and Techniques \\ Predicted Values \\ Natural History and Pulmonary Function in Health and Disease \\ COPD Controversy \\ Ventilator-Associated Pneumonia \\ The Tube, the Intubation Route, and the Cuff \\ Mechanical Ventilation \\ The Bundle \\ Cost \\ Miscellaneous \\ Summary
}

The purpose of this paper is to review the recent literature related to asthma, COPD, pulmonary function testing, and ventilator-associated pneumonia. Topics covered related to asthma include genetics and epigenetics; exposures; viruses; diet, obesity and exercise; exhaled nitric oxide; and drug therapy ( $\beta$ agonists, macrolides, tiotropium and monteleukast). Topics covered related to COPD include childhood disadvantage factors and COPD; vitamin D deficiency and COPD; $\beta$-blockers and COPD; corticosteroid therapy during COPD exacerbations; oxygen administration during 
pre-hospital transport of patients with COPD exacerbation; and prognosis of patients admitted to the hospital for COPD exacerbation. Topics related to pulmonary function testing include methods and techniques; predicted values; natural history, pulmonary function in health and disease; and the COPD controversy. Finally, the paper includes the following topics related to ventilator-associated pneumonia: the tube, the intubation route, and the cuff; mechanical ventilation; the bundle; and cost. These topics were chosen and reviewed in a manner that is most likely to have interest to the readers of Respiratory Care. Key words: asthma; $\beta$ agonist; $\beta$ blocker; COPD; corticosteroids; exhaled nitric oxide; oxygen therapy; pulmonary function testing; spirometry; ventilator-associated pneumonia; vitamin D. [Respir Care 2011;56(4):488-502. @ 2011 Daedalus Enterprises]

\section{Introduction}

There is an overwhelming volume of new literature relevant to respiratory care practice published each year. Faced with the time demands of work and family, it can be difficult to remain abreast of new evidence. It can be an even greater challenge to filter the literature to what is clinically relevant to one's practice and to update one's practice based on the most recent evidence. At the 56th International Respiratory Congress, members of the RESPIRATORY CARE editorial board presented a series of papers in the theme of "Year in Review." Topics were chosen that are likely to have special interest to the readers of RESPIRATORY CARE. We are pleased to publish these in 2 parts in the Journal. In this, Part 1, we cover asthma, COPD, pulmonary function testing, and ventilator-associated pneumonia.

\footnotetext{
Bruce K Rubin MD MEngr MBA FAARC is affiliated with the Virginia Commonwealth University School of Medicine, Richmond, Virginia. Rajiv Dhand MD FAARC is affiliated with the University of Missouri, Columbia, Missouri. Gregg L Ruppel MEd RRT RPFT FAARC is affiliated with Saint Louis University, St Louis, Missouri. Richard D Branson MSc RRT FAARC is affiliated with the University of Cincinnati, Cincinnati, Ohio. Dean R Hess PhD RRT FAARC is affiliated with the Massachusetts General Hospital and Harvard Medical School, Boston Massachusetts; he is also Editor in Chief of RESPIRATORY CARE.
}

Dr Rubin has disclosed relationships with Nostrum Pharmaceuticals, Pharmaxis, Fisher \& Paykel, Novartis, Philips Respironics, MAP Pharmaceuticals, MedImmune, RegenRx, GlaxoSmithKline, Gilead Sciences, Reckitt Bencksier, McNeil Consumer Health, Pfizer Home Health, and Telefex Medical. Dr Dhand has disclosed relationships with GlaxoSmithKline, Novartis, Dey, and Aggenix. Mr Ruppel has disclosed relationships with Medical Graphics, Gilead Sciences, GlaxoSmithKline, and Biomedical Systems. Mr Branson has disclosed relationships with Ikaria, Covidien, Hamilton, General Electric, Newport, and CareFusion. Dr Hess has disclosed relationships with Philips Respironics, Pari, and Covidien.

Correspondence: Dean R Hess PhD RRT FAARC, Respiratory Care, Ellison 401, Massachusetts General Hospital, 55 Fruit Street, Boston MA 02114. E-mail: dhess@ partners.org.

DOI: $10.4187 /$ respcare.01286

\section{Asthma}

Clinical care and research into asthma is progressing rapidly. For 2010, PubMed listed 4,854 publications related to asthma. Of these many publications, certain themes emerged that were areas of active investigation and discovery.

\section{Genetics and Epigenetics}

With the decoding of the human genome and development of single nucleotide polymorphisms, the ability to conduct genome-wide screening to identify susceptibility genes for complex diseases has become greatly enhanced. One of the more interesting findings relates to the gene HHIP, which has been identified as being associated with both asthma and COPD and is critical for lung development in utero. The Dutch hypothesis from 1961 suggested that a susceptible smoker was likely to be someone who has asthma or allergies in early life and then began smoking. Thus, there is a predisposition to developing COPD in later life. In the study by Weiss and colleagues, the HHIP gene was related to pulmonary function and changes in pulmonary function over time. ${ }^{1}$ Pulmonary function tends to remain the same throughout life. So, if you are born with air flow limitation, you will probably spend your life with a similar degree of air flow limitation.

Many complex diseases like asthma are due to both genetic influences and to modification of gene expression that is potentially inheritable. These heritable modifications of DNA are called "epigenetic" and include DNA methylation, micro RNA, and modifications of histone acetylation. Histone modifications can mediate more rapid responses to environmental influences, and DNA methylation can silence gene expression over a long period of time. Environmental influences that can produce epigenetic changes include tobacco smoke (including in utero smoke exposure), polycyclic aromatic hydrocarbons, endotoxin, diesel exhaust particles, particulate matter, and allergens. These can be sampled by dendritic cells in the immature airway. These cells can then prime naive CD41 $\mathrm{T}$ cells to differentiate into allergic $\mathrm{TH} 2$ cells. Epigenetic 
changes are now recognized as key mechanisms underlying the establishment and maintenance of the $\mathrm{TH} 2$ bias in asthma. $^{2}$

\section{Exposures}

It has been shown that increased acetaminophen use in the first 2 years of life is associated with a significantly increased risk of childhood asthma. ${ }^{3}$ This risk is less after adjusting for the frequency of respiratory infections. However prenatal exposure to acetaminophen predicted current wheeze in children at the age of 5 years and the risk of wheeze increased with increasing number of days of prenatal acetaminophen exposure. ${ }^{4}$

Chlorinated pools may influence airway responsiveness, as chlorine gas is irritating. It was shown that attendance at chlorinated pools before the age of 2 years was associated with an increased risk of bronchiolitis, and infant swimmers who developed bronchiolitis had a higher risk of asthma and respiratory allergies later in childhood. ${ }^{5}$

Environmental tobacco smoke is one of the strongest predictors of chronic respiratory illness in children, including the development of asthma. There are now data that show that in utero smoke exposure can increase airway responsiveness to methacholine among children with asthma. Moreover, intrauterine smoke exposure blunts the beneficial effects of inhaled corticosteroids (ICS) on airway hyper-responsiveness in children with asthma. ${ }^{6}$

One of the most interesting recent studies evaluated all hospital admissions for asthma in children under 15 years of age in Scotland, before and after a complete ban on smoking in public places was established in March 2006. Before this legislation, admissions for asthma were increasing at a mean rate of 5.2\% per year, but after March 2006 there was a decrease in the rate of admissions of $18.2 \%$ per year. There was no interaction between hospital admission for asthma and age group, sex, urban or rural residence, or socioeconomic status. ${ }^{7}$

\section{Viruses}

Viruses are the most common precipitant of acute asthma in children. In North America, respiratory syncytial virus (RSV) bronchiolitis in the first year of life has been thought to be an asthma-like condition that can predispose to later asthma. Palivizumab (Synagis) is effective in preventing RSV disease in infants. Despite this, palivizumab given to preterm infants did not decrease the frequency of recurrent wheezing in children with a family history of atopy when compared to matched children who did not receive palivizumab. ${ }^{8}$ It is still possible that RSV may predispose to recurrent wheezing, but in an atopy-independent mechanism.
A new group of human rhinoviruses, group C (HRVC), was recently identified. Asthma severity was assessed in a group of acutely ill children between the age of 2 and 16 on presentation to an emergency department, and respiratory viruses were identified in nasal aspirates. Over $85 \%$ of these children had moderate to severe asthma, and $99 \%$ were admitted to hospital. Human rhinoviruses (all groups) were detected in $87.5 \%$ of these children and other respiratory viruses in only $14.8 \%$, most of whom also had rhinovirus. HRVC was present in 59.4\% of these children and was associated with more severe asthma. ${ }^{9}$

\section{Diet, Obesity and Exercise}

In North America, obesity is epidemic among children and adults. Furthermore, asthma is more common in people with obesity, and asthma in the obese patient is more difficult to treat. Between 1995 and 2005, cross-sectional studies were performed in 29 centers in 20 countries on allergic disease and exposure factors for over 50,000 randomly selected school children. More frequent consumption of fruits, vegetables, and fish was associated with a lower lifetime prevalence of asthma, whereas high consumption of hamburgers was associated with higher lifetime asthma prevalence, but none of these foods were associated with allergic sensitization. Food selection according to the Mediterranean diet was associated with a lower prevalence of asthma $(P=.03) .{ }^{10}$

A cross-sectional study of almost 18,000 school children under the age of 12 living in rural West Virginia showed that obese children were likely to be diagnosed with asthma, but regardless of their body mass index (BMI) percentile, children with asthma were more likely to have higher triglyceride levels and acanthosis nigricans. ${ }^{11}$ In another large study looking at weight gain and asthma risk, BMI was measured in over 100,000 subjects born in the 1950s. The relative risk of asthma associated with a 3-unit increase in BMI was 1.14 in current smokers and 1.27 in never smokers, even after adjusting for confounders. ${ }^{12}$ On the other hand, obesity has also been shown to be associated with asthma misdiagnosis. It has been reported in several studies that about $30 \%$ of adults are incorrectly diagnosed as having asthma. ${ }^{13}$ In a study of almost 500 subjects with physician-diagnosed asthma, older subjects, men, and those with higher $\mathrm{FEV}_{1}$ were more likely to have asthma misdiagnosed. But, more importantly, obese individuals who made urgent visits for respiratory symptoms were far more likely to receive a misdiagnosis of asthma (odds ratio 4.08). The authors also confirmed that obese people with asthma have lower lung function and more comorbidities compared with normal weight people with asthma. ${ }^{14}$

Vitamin D deficiency appears to be extremely common and associated with increased risk of cancer, heart disease, 
and asthma. In 100 children assessed for $25-\mathrm{OH}$ vitamin D levels, $47 \%$ had insufficient levels $(<30 \mathrm{ng} / \mathrm{mL})$ and $17 \%$ were deficient with $<20 \mathrm{ng} / \mathrm{mL}$. FEV $\mathrm{FE}_{1}$ percent of predicted was positively correlated with vitamin D level $(P=.004)$. Vitamin D deficiency was associated both with an increased risk of asthma and with steroid resistance. ${ }^{15}$ Vitamin D may decrease the response to steroids. In adults with asthma, low vitamin D levels were associated with increased airway hyper-responsiveness and reduced response to ICS. ${ }^{16}$

Exercise can trigger asthma in some patients, and for that reason some children and adults with asthma have been cautioned against vigorous exercise. However, studies suggest that exercise is beneficial for asthmatics. After 3 months of an aerobic exercise training program, healthrelated quality of life significantly improved in subjects with asthma, compared with control asthmatics $(P<.001)$ and the number of asthma-free days and anxiety and depression levels also significantly improved. ${ }^{17}$ In ovalbumin-sensitized mice, a common model of asthma, aerobic exercise decreased total lung resistance by $60 \%$, and, more interesting, exercise decreased airway smooth muscle thickness. ${ }^{18}$

\section{Exhaled Nitric Oxide}

Asthma monitoring using the concentration of exhaled nitric oxide (FeNO) has gained wider use in the last few years. FeNO and features of asthma were determined in 175 subjects with severe asthma enrolled in the National Heart Lung and Blood Institute Severe Asthma Research Program, and in 271 with non-severe asthma and 49 healthy subjects. FeNO levels were similar among subjects with severe and non-severe asthma, but subjects with high FeNO had greater airway reactivity to methacholine, more sputum eosinophils, more evidence of atopy, more hyperinflation, but significantly decreased awareness of their symptoms. ${ }^{19}$ In a study of 29 subjects with severe refractory asthma compared with 27 with moderate asthma and 17 healthy controls, FeNO greater than 19 ppb identified those with predominantly eosinophilic asthma. FeNO was lower in subjects with neutrophils in their sputum, regardless of whether eosinophils were present. ${ }^{20}$ Single breath (SB)FeNO was measured in 44 children under the age of 2 years with recurrent wheezing. SB-FeNO was higher in infants with bronchodilator responsiveness $(P<.001)$ and was associated with a lower $\mathrm{FEV}_{0.5}$ measured by the chest compression technique. SB-FeNO was superior to lung function and bronchodilator responsiveness in predicting subsequent wheezing and steroid responsiveness. ${ }^{21}$ In adults, the degree of FeNO elevation has been shown to be an independent predictor of asthma severity, and, among patients with severe asthma, identifies the most reactive asthma phenotype. ${ }^{19}$
FeNO has also been used to assess responsiveness to ICS. Subjects with suboptimal asthma control had a stepwise increase in treatment with maximal fluticasone-salmeterol for a month. Those who remained uncontrolled received oral corticosteroids for an additional month. With this approach, 53/102 subjects or 52\% gained control. Those who achieved control were more likely to have positive skin prick tests for allergies, positive bronchodilator response, and FeNO $>30 \mathrm{ppb}$. FeNO had a sensitivity of $87.5 \%$ and a specificity of $90.6 \%$ in identifying the steroid responsive asthmatics. ${ }^{22}$

\section{Drug Therapy: $\beta$ Agonists, Macrolides, Tiotropium, and Monteleukast}

The use of long-acting $\beta$ agonists (LABA) as monotherapy has been associated with increased risk of asthma death, but there are few data evaluating if steroids attenuate this risk. A meta-analysis was conducted of asthmarelated deaths in randomized controlled clinical trials from the GlaxoSmithKline database comparing salmeterol with non-LABA treatment in asthma. Two large studies (SMART and SNS) contributed $86 \%$ of the asthma deaths. Salmeterol monotherapy was shown to significantly increase the risk of asthma mortality but there was no evidence that the combination of salmeterol and fluticasone was associated with an increased risk. ${ }^{23}$

In 2010, 2 studies of intravenous monteleukast as adjunctive therapy for acute asthma reported conflicting results. In children, a randomized controlled trial in acute asthma showed intravenous monteleukast to have no effect on pulmonary function, symptoms, or clinical course. ${ }^{24}$ In contrast, in a study of 583 adults with acute asthma treated with $7 \mathrm{mg}$ of intravenous monteleukast or placebo, the intravenous monteleukast group had a small but significant increase in pulmonary function. However, this did not change the frequency of admission to hospital or longterm outcome. ${ }^{25}$

Ipratropium bromide has been used for the treatment of acute asthma and has been shown to be synergistic with $\beta$ agonists. There have been few studies on anticholinergic therapy for asthma outside of the emergency department. A 3-way randomized crossover trial in 210 adult subjects with inadequately controlled asthma evaluated the addition of tiotropium bromide to ICS compared with doubling the ICS dose or adding a LABA. The use of tiotropium was superior to a doubling dose of ICS as assessed by morning peak flow, the proportion of asthma control days, pulmonary function (the improvement was also greater than adding a LABA), and symptom scores. ${ }^{26}$

Statin drugs have also been shown to be anti-inflammatory. A study was undertaken in 51 subjects with asthma and sputum eosinophils to determine if adding simvastatin would improve asthma control. There was no significant 
difference in the ICS dose required to achieve control between subjects receiving simvastatin and placebo. ${ }^{27}$

Macrolide antibiotics also have been shown to have immunomodulatory effects, and there have been several studies suggesting benefit in using low dose macrolides for treating asthma. A study population of 92 adults with asthma entered into a randomized trial to evaluate the effect of 16 weeks of clarithromycin added to an ICS therapy. Clarithromycin was shown to improve bronchial hyper-responsiveness, increasing the PC20 methacholine by $1.2 \pm 0.5$ doubling doses $(P=.02) .^{28}$

A very important study evaluated step-up therapy in 182 children, 6-17 years of age, who had uncontrolled asthma despite receiving $100 \mu \mathrm{g}$ twice daily of fluticasone aerosol. Children were randomly assigned to receive a higher dose of twice daily fluticasone $(250 \mu \mathrm{g}), 100 \mu \mathrm{g}$ fluticasone with an addition of $50 \mu \mathrm{g}$ of LABA twice daily, or $100 \mu \mathrm{g}$ fluticasone twice daily plus 5 or $10 \mathrm{mg}$ of a leukotriene receptor antagonist (LRTA) once daily. A triple crossover design was used and a composite of asthma exacerbations, control days, and $\mathrm{FEV}_{1}$ was used to determine if there was a differential response. A differential response occurred in 161 of the 165 subjects. The response to LABA step up was most likely to be the best response, but this was highly variable and many children had a best response to ICS or LTRA step up. Hispanic and nonHispanic white children were more likely to have a best response to LABA step up therapy, and black children were equally likely to have the best response to LABA or ICS step up. Children who did not have eczema were most likely to have the best response to LABA step up $(P=.006){ }^{29}$

\section{Other Studies}

Asthma is associated not only with bronchial hyperresponsiveness but also with mucus retention. Ciliary beat frequency and beat pattern were measured in epithelial strips from 7 subjects with mild, 7 with moderate, 19 with severe asthma, and 9 controls. Ciliary beat frequency was decreased in moderate and severe asthma compared to controls $(P<.01)$, and dyskinesia and motility indexes were highest in severe asthma. Abnormalities were strongly related to the severity of disease $(P<.001)$. This could be one reason for poor mucus clearance in patients with asthma. ${ }^{30}$

One of the more unusual and exciting studies from 2010 evaluated the presence of bitter taste receptors in the airway. Bitter taste receptors on the tongue evolved to evoke signals to avoid ingesting certain plant toxins. The bitter receptors, TAS2R, were also found on human airway smooth muscle, and bitter agonists such as chloroquine and denatonium increased intracellular calcium in airway smooth muscle in a receptor dependent manner. Normally, this would be expected to evoke muscle contraction, but, paradoxically, the bitter tastants caused relation in the smooth muscle and dilatation of airways that was 3 times greater than that elicited by a $\beta$ adrenergic receptor agonist! ${ }^{31}$ This suggests a potentially novel treatment for asthma.

\section{COPD}

COPD affects an estimated 24 million adults and is the fourth leading cause of death in the United States. ${ }^{32}$ A growing body of literature attests to the importance of this disease as a leading public health problem.

\section{Childhood Disadvantage Factors and COPD}

Epidemiological studies in adults have established the relationship of smoking, occupational exposures, exposure to biomass fuels, and respiratory infections with development of COPD. ${ }^{32}$ There has been lesser emphasis on the influence of lung development in childhood on subsequent occurrence of COPD later in life. ${ }^{33}$

Svanes et $\mathrm{a}^{134}$ analyzed data from the European Community Respiratory Health Survey (ECRHS) that included a multicultural population with wide variations in prevalence of COPD. Standardized spirometric measurements as well as extensive interview data were obtained. ECRHS I was conducted at 29 centers from 1991 to 1993, and included 13,359 adults ages 20-44 years. A follow-up survey (ECRHS II) was conducted at 28 centers from 1998 to 2002 , with a mean follow-up of 8.9 years. This survey included 7,738 subjects (ie, 58\% of the original cohort). The investigators performed a cross-sectional analysis of lung function and COPD, using data from both ECRHS I and ECRHS II. They also performed a longitudinal analysis of lung function decline for subjects with lung function data in both ECRHS I and ECRHS II. Five childhood disadvantage factors were identified to significantly $(P<.001)$ influence adult $\mathrm{FEV}_{1}$ after adjusting for smoking, education, social class, height, age, and center. These childhood disadvantage factors included (1) a history of maternal asthma, (2) paternal asthma, (3) asthma in childhood, (4) severe respiratory tract infection below 5 years of age, and (5) maternal smoking. The diagnosis of asthma as a child carried the strongest risk, with 10 -fold higher risk of stage 2 COPD in men and 4-fold higher risk of stage 2 COPD in women. In comparison to smoking, the childhood disadvantage factors were equally prevalent in the general population, had an equally large impact on lung function and development of COPD, with a slightly smaller impact on lung function decline.

The importance of recognizing these childhood disease factors is that prevention programs for COPD could be initiated at a much younger age than is currently practiced. 
Respiratory therapists could play an especially important role in providing education about maternal smoking during pregnancy and the perinatal period, and to increase the focus on early detection and treatment of childhood asthma. Other prevention efforts should aim to increase vaccination rates against common lower respiratory tract infections and provide closer follow-up for subjects with childhood disease factors.

\section{Vitamin D Deficiency and COPD}

Vitamin D deficiency is well known to accelerate osteopenia and osteoporosis. In recent years, vitamin D deficiency has also been correlated with a higher prevalence of cancers, autoimmune disease, infections, and cardiovascular diseases. ${ }^{35}$ There is an unexpectedly high prevalence of vitamin D deficiency among the elderly population in the United States and Europe, with an estimated 40-70\% of this population having low circulating levels of 25hydroxyvitamin D (25-OHD, levels below $20 \mathrm{ng} / \mathrm{mL}$ or $50 \mathrm{nmol} / \mathrm{L}){ }^{36-38}$ In healthy subjects included in the National Health and Nutrition Examination Survey (NHANES III), 25-OHD levels were found to significantly correlate with $\mathrm{FEV}_{1}$ and forced vital capacity (FVC). ${ }^{38}$

Janssens et al ${ }^{39}$ included 414 individuals who were not taking vitamin D supplements, $>50$ years of age, with a history of smoking $>15$ pack-years. Unlike previous investigators, they compared patients with COPD versus a group matched for age, sex, and smoking history but without COPD. In patients with COPD, they found a significant correlation between 25-OHD levels and $\mathrm{FEV}_{1}$. A higher proportion of patients with Global Initiative for Chronic Obstructive Lung Disease (GOLD) stage 3 or 4 COPD had low 25-OHD levels compared to smokers with normal lung function $(P<.001)$. The investigators also determined the effects of variants in the rs7041 and rs 4588 vitamin D binding genes on 25-OHD levels. Among homozygous carriers of the rs7041 at risk T allele, 25\% of patients had low 25-OHD levels. Logistic regression analysis with adjustment for age, sex, and smoking history revealed that homozygous carriers of the rs7041 $\mathrm{T}$ allele had an increased risk of COPD (odds ratio 2.11, 95\% CI 1.20-3.71).

Both environmental and genetic factors probably contribute to development of vitamin $\mathrm{D}$ deficiency in patients with COPD. Because of the high prevalence of vitamin D deficiency in patients with severe or very severe COPD, supplementation with vitamin D should be considered for this group of patients.

\section{$\beta$-Blockers and COPD}

Cardiovascular diseases are common in patients with COPD and account for most deaths in these patients. ${ }^{40,41}$ $\beta$-blockers are highly efficacious for treatment of congestive heart failure and ischemic heart disease and can significantly reduce mortality due to these disorders. ${ }^{42,43}$ Physicians avoid using $\beta$-blockers in patients with COPD and concurrent cardiovascular disease because of concerns about adverse pulmonary effects and their effect on response to $\beta$-agonist bronchodilators. ${ }^{44}$

Rutten et $\mathrm{al}^{45}$ questioned whether long-term $\beta$-blocker use improves survival and reduces risk of exacerbations in patients with COPD. This observational cohort study was conducted in the Netherlands, where all residents, except nursing home residents, are registered with a general practitioner. The investigators employed a network electronic database from 35 general practitioners in 23 practices. Data from January 1995 to December 2005 were screened for patients with a diagnosis of COPD. The study group comprised 2,230 patients with a mean age of 64.8 years. $\beta$-blockers were prescribed in $29.8 \%$ of the patients, and the majority (24.4\%) received cardio-selective $\beta$-blockers. During a mean follow-up period of 7.2 years, $30.8 \%$ of the patients died: $27.2 \%$ of those who used a $\beta$-blocker, compared with $32.3 \%$ of those who did not use a $\beta$-blocker $(P=.02)$. At least one exacerbation occurred in $47.3 \%$ of the patients; $42.7 \%$ of those using a $\beta$-blocker and $49.3 \%$ of those who did not $(P=.005)$. The crude and adjusted hazard ratios with Cox regression analysis of $\beta$-blocker use for mortality were 0.70 (95\% CI $0.59-0.84)$ and 0.68 (95\% CI 0.56-0.83), respectively, whereas the crude and adjusted hazard ratios for exacerbation of COPD were 0.73 (95\% CI $0.63-0.83)$ and 0.71 (95\% CI $0.60-0.83$ ), respectively.

Thus, long-term $\beta$-blocker use, especially with cardioselective $\beta$-blockers, may improve survival and decrease risk of COPD exacerbation in patients with COPD. The concurrent administration of inhaled medications does not interfere with results of $\beta$-blocker use. If indicated, cardioselective $\beta$-blockers should be prescribed in patients with COPD. A randomized controlled trial is needed to address this important observation.

\section{Corticosteroid Therapy During COPD Exacerbations}

Corticosteroid therapy during COPD exacerbation improves lung function, reduces the risk of treatment failure, and reduces hospital stay. ${ }^{46,47}$ Guidelines by experts in the United States, United Kingdom, and Europe recommend low doses of corticosteroids given orally for treatment of COPD exacerbation. ${ }^{48-50}$

Lindenauer et al ${ }^{51}$ performed a retrospective cohort study from a database of 414 hospitals in the United States, mainly small to medium non-teaching hospitals, serving a largely urban population. Patients admitted between January 2006 and December 2007 who were $>40$ years old and had a principal diagnosis of COPD exacerbation or 
acute respiratory failure with a secondary diagnosis of COPD with exacerbation of emphysema were included in the analysis. Those patients who were treated with systemic corticosteroids during the first 2 hospital days were analyzed even if the dose and route of administration were later changed during the hospital course. The primary outcome was a composite measurement of treatment failure that included initiation of mechanical ventilation after the 2nd hospital day, death in hospital, or readmission for COPD exacerbation within 30 days of discharge.

The study included 79,895 patients, with a median age of 69 years. Initial high dose corticosteroid therapy was instituted in 73,765 patients (92\%), median $600 \mathrm{mg}$, IQR 350-781 mg, whereas initial low dose corticosteroid therapy was instituted in only 6,220 patients $(8 \%)$, with a median dose of $60 \mathrm{mg}$, IQR 40-120 mg. The therapy was switched from initial low dose to high dose therapy in 1,356 patients $(22 \%)$. There were differences between the groups receiving high dose versus low dose corticosteroids in terms of age, race, insurance status, region, comorbidities, and other therapies employed during hospital stay. The composite end point of treatment failure occurred in $10.9 \%$ of patients receiving high dose and $10.3 \%$ of patients receiving low dose corticosteroids. Further analysis of the data to adjust for a propensity matched cohort and balanced covariates to correct for remaining differences between the groups showed a slightly lower risk of treatment failure, shorter hospital stay, and lower hospital costs in the group receiving low dose corticosteroids. Lower doses of oral corticosteroids should be preferred for patients admitted to the hospital for COPD exacerbation, provided they are not admitted to an intensive care unit (ICU).

\section{Oxygen Administration During Pre-hospital Transport of Patients With COPD Exacerbation}

The pre-hospital transport of patients with COPD exacerbation includes nebulized bronchodilators (most powered with $\mathrm{O}_{2}$ ), oxygen, and corticosteroids. Administration of oxygen treats hypoxemia, but is often associated with development or worsening of hypercapnia. ${ }^{52,53}$

Recent audits of patients admitted to the hospital for COPD exacerbation have shown that administration of high flow oxygen is associated with increased mortality, longer hospital stay, need for mechanical ventilation, and admission to high dependence units. ${ }^{54,55}$ In contrast, the use of titrated oxygen treatment for in-hospital patients with COPD exacerbation is associated with lesser acidosis, a lower requirement for mechanical ventilation, and reduced mortality. ${ }^{56}$

Austin et al ${ }^{57}$ conducted a randomized controlled trial to determine if routine administration of high oxygen con- centrations in the pre-hospital setting to patients with COPD exacerbation is associated with increased mortality. In this trial, paramedics (not patients) were randomized. The trial was conducted between June 2006 and July 2007, and 405 patients with presumed COPD were transported by ambulance. Among this group, the diagnosis of COPD was confirmed by pulmonary function tests in 214 patients. High flow oxygen was administered via non-rebreathing mask at $8-10 \mathrm{~L} / \mathrm{min}$, and the nebulizer was driven by $\mathrm{O}_{2}$ at $6-8 \mathrm{~L} / \mathrm{min}$. Low flow oxygen was administered via nasal cannula and titrated to an $\mathrm{S}_{\mathrm{pO}_{2}}$ of $88-92 \%$, via pulse oximetry. In this latter group, the nebulizer was powered by air, and aerosol was delivered via mask. Patients also received standard therapy for COPD exacerbation. All deaths occurred after arrival to the hospital. Respiratory failure was the primary cause of death, and most (70\%) deaths occurred within 5 days of admission. The mortality rate was $9 \%$ in patients who received high flow oxygen and $4 \%$ in those who received low flow oxygen. In the subgroup of patients with confirmed COPD, mortality was $9 \%$ in those who received high flow oxygen and $2 \%$ in those who received low flow oxygen. Compared to the high flow arm, the use of low flow oxygen reduced mortality by $58 \%$ in all patients (relative risk $0.42,95 \%$ CI $0.20-0.89, P=.02$ ), and by $78 \%$ in the group with confirmed COPD (relative risk 0.22 , 95\% CI $0.05-0.91$, $P=.04)$.

Thus, uncontrolled oxygen therapy during pre-hospital transport may be detrimental in patients with COPD exacerbation, with the number needed to harm of 14 . In the pre-hospital setting, uncontrolled oxygen therapy should be avoided, and oxygen should be titrated to achieve an $\mathrm{S}_{\mathrm{pO}_{2}}$ of $88-92 \%$.

\section{Prognosis of Patients Admitted to the Hospital for COPD Exacerbation}

Within the past $10-15$ years, several guidelines have been published in an effort to improve the prognosis of patients with COPD. In a prospective cohort study, Almagro et a ${ }^{58}$ determined whether long-term mortality after discharge from a hospitalization related to COPD had improved in recent years. The authors studied 2 cohorts 7 years apart (135 participants enrolled from November 1996 to May 1997, and 181 participants enrolled from June 2003 to September 2004). All consecutive patients admitted for COPD exacerbation at one hospital were included, and their comorbidities and treatments were assessed, with follow-up for up to 3 years after discharge. The patients had at least moderate COPD, measured via spirometry. The cohorts were comparable in baseline age, sex, comorbidities, functional status, number of hospitalizations, and COPD exacerbations in the previous year. The 3 -year mor- 
tality was lower in the 2003-2004 cohort than in the 19961997 cohort ( $38.7 \%$ vs $47.4 \%$, respectively, $P=.02$ ). The relative risk of death after adjustment for age, body mass index, comorbidities, lung function, and modified Medical Research Council dyspnea scale was 0.66 (95\% CI $0.45-$ 0.97). This improvement in prognosis of patients admitted to the hospital for COPD exacerbation is probably due to standardized COPD management, better management of comorbidities, and possibly the impact of cardiovascular medications on survival.

\section{Pulmonary Function Testing}

\section{Pulmonary Function Testing Methods and Techniques}

Spirometry is the accepted standard for diagnosing airway obstruction, particularly in making the diagnosis of COPD. It is also useful in differentiating reversible and non-reversible airway obstruction when combined with a bronchodilator trial. Some studies have suggested that spirometry done in primary care settings can be useful, but the quality of the spirometry may be lacking, and this can affect interpretation.

Borg et al ${ }^{59}$ measured how frequently spirometry in a primary care setting met the American Thoracic Society (ATS) criteria, and compared spirometry done by local users to that done by a trained specialist. Even after 14 hours of spirometry training, the primary care users failed to perform spirometry at a consistent level of acceptability. Acceptability criteria were often not met, but repeatability criteria were. The spirometers used did not display flow-volume and volume-time tracings in real time, and may have contributed to the poor rate of acceptability. Only 57\% of maneuvers met all ATS/European Respiratory Society (ERS) criteria; $81 \%$ met the criteria for 2 acceptable efforts.

Masa et al ${ }^{60}$ investigated whether spirometry could be performed remotely, utilizing personnel from a hospital to prompt the patient to perform the required maneuvers. Patients were randomized to be tested either in-person or remotely. Using 2 different approaches, intention to treat and protocol, there was almost no difference (bias) between the methods. The intention-to-treat grouping, analyzed using difference plots (Bland-Altman) showed the limits of agreement of about $350 \mathrm{~mL}$ for FVC and $300 \mathrm{~mL}$ for $\mathrm{FEV}_{1}$. The protocol group yielded similar results. Online spirometry compared favorably; it took slightly longer (by about a minute) and required approximately one additional maneuver.

Body plethysmography to measure lung volumes is regarded as the accepted standard because it is minimally affected by maldistribution of ventilation, as compared to the gas dilution techniques. However, plethysmography can overestimate lung volume when the patient pants too rapidly or alveolar pressure is measured incorrectly for other reasons. Accurate lung volumes are used to assess air trapping and hyperinflation in patients who have obstructive lung disease, and have been recently used to evaluate response to therapies aimed at reducing these defects.

O'Donnell et al ${ }^{61}$ compared computed tomography (CT) to lung volume measured via plethysmography and via helium dilution. They looked at a range of patients in 3 centers, including subjects with severe airway obstruction $\left(\mathrm{FEV}_{1}<30 \%\right.$ predicted). The CT measurements were single maneuvers and measured total lung capacity directly, with the patient in a supine position. One center corrected for spirometric differences during the CT measurement. Helium dilution used a standard technique but was measured only once. Not surprisingly, CT derived lung volumes compared favorably with the helium dilution technique, and both were significantly lower than plethysmographically derived lung volumes. The mean difference in patients who had airway obstruction was approximately $1 \mathrm{~L}$ (plethysmography vs either CT or helium dilution). These data suggest that plethysmography may overestimate lung volumes even when done correctly, and that when lung volumes are used to make therapeutic decisions, the method of measurement may become important.

\section{Predicted Values}

Interpretation of spirometry depends on the use of appropriate reference data from a normal healthy population. The NHANES III reference set has been recommended for use in the United States, but has a lower age range of 8 years of age. In addition, separate regression coefficients are required to accommodate pediatric/adolescent subjects and adults. The variability of the common spirometric measures is assumed to be constant across ages in adults.

Stanojevic et al $^{62}$ used the lambda, mu, sigma (LMS) statistical modeling approach (as used to produce growth charts for children) to account for the variability in spirometric measures at each age and height. Data from other studies of young children were combined with the NHANES III data to extend the lower age limit to 3 years and provide a smooth transition between the youngest children, adolescents, and adults. This is particularly important because of the rapid increase in lung function during the first 10 years of life and the changes that occur during adolescence. These all-age equations account for the between individual variability (age-dependent). The largest variability is in children $<$ age 11 years, but there is also increasing variability with advancing age ( $>30$ years). This approach uses $\mathrm{z}$-scores, which take into account age and height related variability.

Lung function might be expected to change as a result of nutrition, environment, and availability of healthcare or other factors. As a result, predicted values might vary over time. ATS/ERS guidelines suggest that pulmonary func- 
tion laboratories evaluate reference equations for local use, but it is not clear how large a sample population might be needed to perform this type of validation.

Quanjer et al ${ }^{63}$ evaluated a large database collected as part of the Global Lungs initiative. Thirty spirometry data sets from whites over a period of 30 years were compared using GAMLSS (Generalized Additive Models for Location Scale and Shape) modeling to calculate mean z-scores for $\mathrm{FEV}_{1}$. There does not seem to be a trend of either increasing or decreasing $\mathrm{FEV}_{1}$ from the period 1980 to 2010. This finding was somewhat unexpected, but suggests that older reference equations remain valid.

Quanjer ${ }^{63}$ also subdivided healthy subjects from a large population study (Health Survey for England) into different, randomly selected, smaller subsets to evaluate differences due to sample population and technique. When the data sets were large ( $>1,000$ persons), the $\mathrm{z}$-scores for variables like $\mathrm{FEV}_{1}$ were small. Small sample sizes resulted in increased $\mathrm{z}$-scores. The authors concluded that at least 150 males and 150 females would be needed to validate reference values to avoid spurious differences due to sampling error. Unfortunately, this type of study is beyond the scope of most pulmonary function laboratories.

Although NHANES III has been recommended for use in the United States (for whites, African-Americans, and Hispanics) it has not been formally validated. A correction factor for Asian-Americans of 0.94 was based on 2 studies that included young and old subjects but not many in between. NHANES III was also not validated in patients older than age 80 . Hankinson et al ${ }^{64}$ used spirometry performed as part of the Multi-Ethnic Study of Atherosclerosis (MESA) Lung Study to address some of these issues. The equations for whites, African-Americans, and Mexican-Americans performed acceptably; the average values were slightly smaller than the predicteds but the differences were less than the repeatability criteria of $150 \mathrm{~mL}$. The authors attributed these small differences to methodological differences. There was also excellent agreement for classifying abnormal lung function by the lower limit of normal (LLN). The largest discrepancies (observedpredicted) were seen in African-American men and in Hispanics of non-Mexican origin. Observed values for AsianAmericans were significantly lower than predicted values, even when the suggested 0.94 correction factor was applied. The authors suggest that a factor of 0.88 may be more appropriate for Asian-Americans, particularly those of Chinese ancestry. The differences for Asian-Americans tend to be less at age 70 and above. For subjects over age 80 , the NHANES III predicteds underestimated the observed value (most likely survivor bias), but there were no extreme differences, so that NHANES III can be used without significant misclassification.

\section{Natural History and Pulmonary Function in Health and Disease}

$\mathrm{FEV}_{1}$ percent of predicted is widely used to classify or categorize the severity of obstructive lung disease. $\mathrm{FEV}_{1}$ is a predictor of all cause mortality as well as for mortality related to respiratory disease. The usual approach has been to arbitrarily select percent of predicted thresholds to classify severity (eg, $80 \%$ as normal, $50 \%$ separating moderate from severe).

Miller and Pedersen ${ }^{65}$ evaluated spirometry data from 3 large studies: the University Hospital Birmingham (11,972, 53\% male), the Copenhagen City Heart Study 1976-2002 (13,900, 46\% male), and 1,095 COPD patients for whom survival data were available. The investigators compared various indices (percent of predicted, SR, $\mathrm{FEV}_{1} / \mathrm{Ht}^{3}, \mathrm{FEV}_{1} /$ $\mathrm{Ht}^{2}$, and a new parameter, $\mathrm{FEV}_{1} \mathrm{Q}$ ) to see which bestpredicted mortality. The new metric, $\mathrm{FEV}_{1} \mathrm{Q}$, expresses impairment as the number of turnovers of the nominal lower limit (based on the lowest 1 percentile) of lung function remaining. Instead of looking at how much function is lost, $\mathrm{FEV}_{1} \mathrm{Q}$ looks at how much is left. The $\mathrm{FEV}_{1} \mathrm{Q}$ and $\mathrm{FEV}_{1} / \mathrm{Ht}^{3}$ performed better than percent of predicted or even the SR. The percent of predicted fails because it is markedly different in young and old subjects with severe lung disease. The SR (z-score) has similar limitations. The authors recommend rethinking how to best categorize obstructive lung disease.

The $\mathrm{FEV}_{1} / \mathrm{FVC}$ in children has been considered to fall with age, just as in adults, and this assumes that the ratio of residual volume to total lung capacity (RV/TLC) remains constant. Because of changes in the airways, body proportions, thoracic shape, and respiratory muscle function that occur during growth, the age dependence of $\mathrm{FEV}_{1} /$ FVC and RV/TLC is unknown. Quanjer et al ${ }^{66}$ combined several large groups of children from around the world and fitted spirometry data for age, height, and sitting height (from 3 centers). In childhood, FVC outgrows TLC and $\mathrm{FEV}_{1}$, leading to a fall in $\mathrm{FEV}_{1} / \mathrm{FVC}$ and RV/TLC. However, these trends tend to reverse in adolescence. Sitting height reduces the differences in pulmonary function within and between various ethnic groups. The highest $\mathrm{FEV}_{1} /$ FVC ratios occur in the children who are shortest for their age. These changes need to be considered for interpretation of pulmonary function tests, particularly in adolescents where the $\mathrm{FEV}_{1} / \mathrm{FVC}$ may plateau or even increase. Reference equations for children and adolescents need to account for sex, height, age, ethnicity, and ideally sitting height.

Interpretation of spirometry using the 95th percentile as the LLN may not detect mild air flow limitation. Reporting lung function decline to smokers has been suggested as a mechanism to encourage smoking cessation. The current literature is mixed, with most reports showing minimal 
improvement in smoking cessation rates when lung age or spirometry results are used.

Hansen et $a^{167}$ assessed the population of smokers and non-smokers who participated in the NHANES III survey $(n>9,000)$. The odds that a given difference between observed and predicted came from a smoker versus nonsmoker were calculated for $\mathrm{FEV}_{1} / \mathrm{FVC}$ and $\mathrm{FEV}_{1} / \mathrm{FEV}_{6}$. The authors found evidence that air flow obstruction is observable at age 25 and markedly different by age 50 years. As $\mathrm{FEV}_{1} / \mathrm{FVC}$ decreases by a few percentage points from the predicted, the odds increase to above 1. Calculating these odds that lung function has decreased suggests that subtle changes precede the fall into the lowest 5 th percentile. Whether this is any more useful for convincing smokers to quit has yet to be proven. Another study ${ }^{68}$ demonstrated that appropriate reference equations have to be used to predict lung age. Unfortunately, because of the wide variability of the $\mathrm{FEV}_{1}$ and $\mathrm{FEV}_{1} / \mathrm{FVC}$ ratio in healthy subjects, it is difficult to attribute increased lung age (lower observed than predicted) to smoking. It is also not appropriate to allow smokers whose $\mathrm{FEV}_{1}$ is above their mean expected value to continue to smoke. Only serial measurements and trend analysis can tell whether an individual has an increased rate of loss of lung function.

\section{COPD Controversy}

The ATS/ERS interpretation guidelines recommend using a statistically valid LLN for the $\mathrm{FEV}_{1} / \mathrm{FVC}$, along with LLN for TLC and the diffusing capacity of the lung for carbon monoxide $\left(\mathrm{D}_{\mathrm{LCO}}\right)$. Many clinicians still use the 0.70 fixed ratio for defining airway obstruction and $80 \%$ as the LLN for all other parameters (FVC, TLC, $\mathrm{D}_{\mathrm{LCO}}$ ). While the problems caused by using a fixed $\mathrm{FEV}_{1} / \mathrm{FVC}$ ratio have been well documented over the past 5 years, the use of a fixed cut-off of $80 \%$ has persisted.

Miller et al ${ }^{69}$ combined a large population of patients from 3 different countries and used 2 versions of the ATS/ ERS algorithm to classify their disease patterns. The use of the fixed $\mathrm{FEV}_{1} / \mathrm{FVC}$ ratio and $80 \%$ of predicted for $\mathrm{FVC}$, TLC, and $\mathrm{D}_{\mathrm{LCO}}$ was compared to using the LLN (5th percentile) of the same measures. Out of 11,413 patients, about 1,000 more patients were classified as abnormal by the percent-predicted method (3,904 vs 2,808). A total of 2,685 patients had discordant interpretations ( $23.5 \%$ of the entire group). Age and gender bias were noteworthy in the number of asthmatics and emphysema patients when fixed cut-off values were used. Although the ATS/ERS algorithm is somewhat arbitrary and simplistic, in this study it points out the significant differences that can occur depending on how normal is defined.

The LMS statistical method is a new approach that defines the LLN for $\mathrm{FEV}_{1} / \mathrm{FVC}$ as the 5th percentile of the distribution of z-scores. The clinical validity of this thresh- old for defining COPD is unknown. The LMS method takes into account the between-individual variability and more accurately describes how spirometric variables change with age. Using LMS, the z-score accounts for the median (mu) representing how the spirometric variable changes with the predictor variable; for the coefficient of variation (sigma), which models the spread of spirometric reference values and adjusts for non-uniform dispersion; and for skewness (lambda), which models how the variables differ from a normal distribution using a box-Cox transformation.

The LMS-LLN5 is a carefully defined statistical definition of normal, and Vaz Fragoso et al ${ }^{70}$ looked to see if it correlated with death and respiratory symptoms in a subset of NHANES III participants $(40-80$ years, whites with mortality data through 12/31/2000). Subjects were stratified by their $\mathrm{FEV}_{1} / \mathrm{FVC}$ set at progressively higher percentiles. Adjusted hazard ratios for death and odds ratios for respiratory symptoms only exceeded 1.0 for those with ratios < LMS-LLN5 (subjects in the LMS-LLN25 percentile were used as the reference group). Both GOLD and the standard LLN (5th percentile) tend to overestimate the presence of air flow obstruction, particularly in the oldest age groups. The standard LLN does not account for the increasing variability seen in healthy older subjects. In other words, the LMS-LLN5 tends to be even lower than the 5 th percentile as normally calculated. The authors conclude that in whites ages 40-80 years, an $\mathrm{FEV}_{1}$ / FVC $<$ LMS-LLN5 identifies persons with increased risk of death and prevalence of respiratory symptoms. The LMSLLN5 should be used as the threshold for establishing COPD.

There has been a great deal of evidence recently published showing that $\mathrm{FEV}_{1} / \mathrm{FVC}$ is age dependent, and is also influenced by height, gender, and ethnicity. Use of the fixed cut-off of 0.70 to define airways obstruction misclassifies older subjects as having COPD (false positives) and younger subjects as being normal when they may have asthma or early COPD (false negatives).

Quanjer et $\mathrm{al}^{71}$ sent an open letter to the members of the GOLD scientific committee requesting that they change the definition of mild airway obstruction. To quote from the letter, "We are therefore appealing to you, members of the GOLD committee, to change the method by which mild airway obstruction is defined by the GOLD guidelines in order to abandon the fixed ratio forever in favor of the lower limit of normal." It references 40 studies or editorials that call the fixed ratio into question. There is a long list of supporting organizations and 147 signatories from 23 countries, including physicians, respiratory scientists, and respiratory therapists involved in lung function testing. Although a very good case can be made for using a statistically valid LLN, the argument can be made that COPD is never diagnosed in an individual patient without 
consideration of the history and physical presentation in addition to spirometry. But the GOLD guidelines have become so entrenched that epidemiologic studies and multicenter drug trials have used them for inclusion/exclusion criteria, introducing significant bias into otherwise well conceived scientific investigations.

\section{Ventilator-Associated Pneumonia}

Ventilator-associated pneumonia (VAP) is a common and serious complication in the intensive care unit. VAP is typically associated with greater costs and increased mortality. Given these facts, the prevention, diagnosis, treatment and monitoring of VAP have been a frequent topic in the recent literature.

\section{The Tube, the Intubation Route, and the Cuff}

While VAP derives its nom de guerre from association with the ventilator, the ventilator is probably only a bystander. Translaryngeal placement of an endotracheal tube appears to be the real risk factor, representing a direct conduit for contamination of the lower airway. Modifications of the structure and material composition of the tube and cuff have occurred in the last year in an effort to prevent VAP.

The original North American Silver Coated Endotracheal Tube Study (NASCENT), published in 2008, demonstrated a reduction in VAP rate in patients intubated with a silver-coated tube. ${ }^{72}$ More recently, Rello et al73 evaluated silver and non-silver-coated tubes in a series of pre-clinical models of early VAP. They demonstrated reduced biofilm adherence to the silver-coated tubes, continued presence of the silver coating out to 21 days, and reduced colonization of silver tubes compared to uncoated tubes. These studies included animal, in vitro, and patient data. Together these data suggest that the silver-coated tube has characteristics that disrupt the early pathogenesis of VAP. In a secondary analysis of the NASCENT trial, Afessa et $\mathrm{al}^{74}$ found that the presence of the silver coated tube was associated with an improved mortality. Patients using traditional tubes had a greater incidence of sepsis, perhaps leading to the mortality difference. These findings suggest that the silver tube, used with appropriate antibiotic coverage, reduces multiple-drug-resistance and accumulation of biofilm, and improves outcome. This is a novel finding, as previous studies without silver-coated tubes demonstrated an increased mortality with late onset of VAP. ${ }^{75}$ These findings have been debated and require further validation. ${ }^{76-78}$

Lacherade et al ${ }^{79}$ undertook a large multicenter trial of continuous subglottic suction endotracheal tubes versus conventional endotracheal tubes. They found that use of the subglottic suction tube was associated with a reduced incidence of both early and late onset VAP, with an absolute risk reduction of $10.8 \%$. They also noted that the use of subglottic suctioning was not associated with evidence of tracheal wall injury or a difference in re-intubation rate secondary to airway edema. The latter finding is important, as this had been an area of concern related to the use of these tubes.

Conventional wisdom has favored tracheostomy over long-term endotracheal intubation for reduction of VAP. However, conflicting data have been presented, which may represent differences in the patient populations studied. Terragni et al ${ }^{80}$ performed a randomized controlled trial of early versus late tracheostomy in 419 patients and found no difference in the incidence of VAP. Nearly every early tracheostomy study suffered from design problems and practical limitations. The important question may not be when (early or late), but who (head injury, the elderly, etc). ${ }^{81}$

The introduction of high-volume low-pressure endotracheal tube cuffs 30 years ago was welcomed as a solution to tracheal injury from high-pressure, low-volume cuffs. More recently, cuff designs have changed to eliminate the common invagination of high-volume low-pressure cuffs, which create a conduit for aspiration of subglottic secretions. Pitts et al ${ }^{82}$ reported reduced leakage around new cuff designs in a silicone model of the trachea. While these in vitro findings support previous findings, limitations of the model prevent generalization of the findings to patients. ${ }^{83,84}$ For example, Dave et al ${ }^{85}$ found that lubricating cuffs in these in vitro models significantly improves the seal. Whether these findings can be repeated in vivo remains to be determined.

\section{Mechanical Ventilation}

Noninvasive ventilation (NIV) probably derives a number of its advantages from elimination of the artificial airway. A Cochrane review by Burns et $\mathrm{al}^{86}$ found that NIV is associated with a reduction in VAP, mortality, and ICU days, compared to invasive ventilation. In this analysis the relative risk for developing VAP was 0.29 (95\% CI 0.19-0.45) in favor of NIV. These findings should be tempered by the preponderance of patients with chronic lung disease in this analysis. Extrapolation to other disease states should be made with caution.

A multicenter, retrospective review of 400 German ICUs, including over 78,000 patients, found that NIV was associated with a VAP rate of 1.6 cases per 1,000 ventilator days. The VAP rate in invasive ventilation was 5.4 cases per 1,000 ventilator days. ${ }^{87}$ While these findings support the Cochrane review, the number of patients receiving NIV in these centers was remarkably low. This probably represents a slow adoption of NIV, even in those patients most likely to benefit. 
In both in vivo and in vitro studies, the use of PEEP is associated with reduced aspiration around the endotracheal tube cuff. ${ }^{83,85,88}$ It is likely that new cuff designs and the use of a minimum level of PEEP combine to reduce silent aspiration. A recent trial of airway pressure release ventilation suggests a reduced VAP rate through a similar mechanism. ${ }^{88}$ This finding provides additional evidence for the use of PEEP in mechanically ventilated patients.

\section{The Bundle}

The use of VAP bundles, a collection of clinical standards, has been promoted as an effective method for reducing VAP. Rello et al ${ }^{89}$ developed a recent bundle with input from a multidisciplinary group using multicriteria decision analysis, which is a technique that supports decision making when numerous and conflicting evaluations are assessed, by weighting and prioritizing procedures. They evaluated procedures in 2 groups: the diagnosis of VAP, and the treatment of VAP. In the diagnostic section the bundle consisted of (in order of importance): early chest radiograph, immediate Gram-stain results, quantitative microbiology prior to antibiotic treatment, blood cultures, invasive specimen sampling prior to antibiotic treatment, and determination of intracellular organism in alveolar lavage fluid. The VAP treatment bundle consisted of (in order of importance): immediate antibiotic treatment following sampling, empirical antibiotic therapy based on local pathogens, de-escalation of antibiotic therapy following identification of organisms, assessment of response to therapy within 72 hours, and use of monotherapy in patients with low risk for multiple-drug-resistant organisms. Additional studies support the use of bundles and, importantly, monitoring of adherence and use of quality improvement to maximize adherence..$^{90,91}$

\section{Cost}

The financial burden of VAP is a concern for patients, caregivers, health systems, and payers. While a case of VAP is often said to add $\$ 40,000$ to hospital costs, a paper by Magret et al ${ }^{92}$ found no difference in ICU stays or costs associated with VAP in trauma patients. In fact, the trend was for lower mortality in trauma patients with VAP. Clearly, patient population affects the response to VAP. Restrepo et $\mathrm{al}^{93}$ found contradictory findings, suggesting VAP increased costs by around $\$ 20,000$ per case. Interestingly, respiratory therapy charges were not different between groups. A main concern of hospitals is the recent suggestion that VAP should be a never event. Data from the NASCENT trial suggest that, while a VAP rate of zero is a laudable goal, it is probably unobtainable. ${ }^{91}$

\section{Miscellaneous}

Use of adjunctive aerosolized antibiotics for the treatment of VAP continues to be explored. Reducing the systemic complications of aminoglycosides is a commonly mentioned advantage. Czosnowski et al ${ }^{94}$ retrospectively reviewed their adjunctive aerosol therapy use in a trauma ICU and found microbiologic success in $77 \%$ of patients. Aerosolized antibiotics were used predominantly in patients failing intravenous monotherapy. Prone positioning, lateral rotation, and lateral position with horizontal position of the endotracheal tube have been described with varying degrees of success in reducing VAP. ${ }^{95-97}$

The use of probiotics to alter gastrointestinal flora and alter VAP rates has been reported, but this idea is early in development. ${ }^{98-100}$ Finally, there continues to be support for a reduced frequency of ventilator circuit changes. ${ }^{101,102}$

\section{Summary}

In this paper the important recent literature on asthma, COPD, pulmonary function testing, and VAP is reviewed. It is our hope that this will help to familiarize the reader with the important literature in these subject areas.

\section{REFERENCES}

1. Weiss ST. What genes tell us about the pathogenesis of asthma and chronic obstructive pulmonary disease. Am J Respir Crit Care Med 2010;181(11):1170-1173.

2. Kabesch M, Michel S, Tost J. Epigenetic mechanisms and the relationship to childhood asthma. Eur Respir J 2010;36(4):950-961.

3. Lowe AJ, Carlin JB, Bennett CM, Hosking CS, Allen KJ, Robertson $\mathrm{CF}$, et al. Paracetamol use in early life and asthma: prospective birth cohort study. BMJ 2010;341:c4616.

4. Perzanowski MS, Miller RL, Tang D, Ali D, Garfinkel RS, Chew GL, et al. Prenatal acetaminophen exposure and risk of wheeze at age 5 years in an urban low-income cohort. Thorax 2010;65(2): 118-123.

5. Voisin C, Sardella A, Marcucci F, Bernard A. Infant swimming in chlorinated pools and the risks of bronchiolitis, asthma and allergy. Eur Respir J 2010;36(1):41-47.

6. Cohen RT, Raby BA, Van Steen K, Fuhlbrigge AL, Celedón JC, Rosner BA, et al; Childhood Asthma Management Program Research Group. In utero smoke exposure and impaired response to inhaled corticosteroids in children with asthma. J Allergy Clin Immunol 2010;126(3):491-497.

7. Mackay D, Haw S, Ayres JG, Fischbacher C, Pell JP. Smoke-free legislation and hospitalizations for childhood asthma. N Engl J Med 2010;16;363(12):1139-1145.

8. Simões EA, Carbonell-Estrany X, Rieger CH, Mitchell I, Fredrick L, Groothuis JR; Palivizumab Long-Term Respiratory Outcomes Study Group. The effect of respiratory syncytial virus on subsequent recurrent wheezing in atopic and nonatopic children. J Allergy Clin Immunol 2010;126(2):256-262.

9. Bizzintino J, Lee WM, Laing IA, Vang F, Pappas T, Zhang G, et al. Association between human rhinovirus $\mathrm{C}$ and severity of acute asthma in children. Eur Respir J 2010;[Epub ahead of print]

10. Nagel G, Weinmayr G, Kleiner A, Garcia-Marcos L, Strachan DP; ISAAC Phase Two Study Group. Effect of diet on asthma and 


\section{Respiratory Care Year in Review 2010: Part 1}

allergic sensitisation in the International Study on Allergies and Asthma in Childhood (ISAAC) Phase Two. Thorax 2010;65(6): 516-522.

11. Cottrell L, Neal WA, Ice C, Perez MK, Piedimonte G. Metabolic abnormalities in children with asthma. Am J Respir Crit Care Med 2010; [Epub ahead of print]

12. Hjellvik V, Tverdal A, Furu K. Body mass index as predictor for asthma: a cohort study of 118,723 males and females. Eur Respir J 2010;35(6):1235-1242.

13. Luks VP, Vandemheen KL, Aaron SD. Confirmation of asthma in an era of overdiagnosis. Eur Respir J 2010;36(2):255-260.

14. Pakhale S, Doucette S, Vandemheen K, Boulet LP, McIvor RA, Fitzgerald JM, et al. A comparison of obese and nonobese people with asthma: exploring an asthma-obesity interaction. Chest 2010; 137(6):1316-1323.

15. Searing DA, Zhang Y, Murphy JR, Hauk PJ, Goleva E, Leung DY. Decreased serum vitamin D levels in children with asthma are associated with increased corticosteroid use. J Allergy Clin Immunol 2010;125(5):995-1000.

16. Sutherland ER, Goleva E, Jackson LP, Stevens AD, Leung DY. Vitamin D levels, lung function, and steroid response in adult asthma. Am J Respir Crit Care Med 2010;181(7):699-704.

17. Mendes FA, Gonçalves RC, Nunes MP,Saraiva-Romanholo BM, Cukier A, Stelmach R, et al. Effects of aerobic training on psychosocial morbidity and symptoms in patients with asthma: a randomized clinical trial. Chest 2010;138(2):331-337.

18. Hewitt M, Estell K, Davis IC, Schwiebert LM. Repeated bouts of moderate-intensity aerobic exercise reduce airway reactivity in a murine asthma model. Am J Respir Cell Mol Biol 2010;42(2):243249.

19. Dweik RA, Sorkness RL, Wenzel S, Hammel J, Curran-Everett D, Comhair SA, et al. Use of exhaled nitric oxide measurement to identify a reactive, at-risk phenotype among patients with asthma. Am J Respir Crit Care Med 2010;181(10):1033-1041.

20. Tseliou E, Bessa V, Hillas G, Delimpoura V, Papadaki G, Roussos $\mathrm{C}$, et al. Exhaled nitric oxide and exhaled breath condensate $\mathrm{pH}$ in severe refractory asthma. Chest 2010;138(1):107-113.

21. Debley JS, Stamey DC, Cochrane ES, Gama KL, Redding GJ. Exhaled nitric oxide, lung function, and exacerbations in wheezy infants and toddlers. J Allergy Clin Immunol 2010;125(6):12281234.

22. Pérez-de-Llano LA, Carballada F, Castro Añón O, Pizarro M, Golpe $\mathrm{R}$, Baloira A, et al. Exhaled nitric oxide predicts control in patients with difficult-to-treat asthma. Eur Respir J 2010;35(6):1221-1227.

23. Weatherall M, Wijesinghe M, Perrin K, Harwood M, Beasley R. Meta-analysis of the risk of mortality with salmeterol and the effect of concomitant inhaled corticosteroid therapy. Thorax 2010;65(1): 39-43.

24. Morris CR, Becker AB, Piñieiro A, Massaad R, Green SA, Smugar SS, Gurner DM. A randomized, placebo-controlled study of intravenous montelukast in children with acute asthma. Ann Allergy Asthma Immunol 2010;104(2):161-171.

25. Camargo CA Jr, Gurner DM, Smithline HA, Chapela R, Fabbri LM, Green SA, et al. A randomized placebo-controlled study of intravenous montelukast for the treatment of acute asthma. J Allergy Clin Immunol 2010;125(2):374-380.

26. Peters SP, Kunselman SJ, Icitovic N, Moore WC, Pascual R, Ameredes BUT, Boushey HA, et al; National Heart, Lung, and Blood Institute Asthma Clinical Research Network. Tiotropium bromide step-up therapy for adults with uncontrolled asthma. N Engl J Med 2010;363(18):1715-1726.

27. Cowan DC, Cowan JO, Palmay R, Williamson A, Taylor DR Simvastatin in the treatment of asthma: lack of steroid-sparing effect. Thorax 2010;65(10):891-896.
28. Sutherland ER, King TS, Icitovic N, Ameredes BT, Bleecker E, Boushey HA, et al; National Heart, Lung, and Blood Institute Asthma Clinical Research Network. A trial of clarithromycin for the treatment of suboptimally controlled asthma. J Allergy Clin Immunol 2010;126(4):747-753.

29. Lemanske RF Jr, Mauger DT, Sorkness CA, Jackson DJ, Boehmer SJ, Martinez FD, et al; Childhood Asthma Research and Education (CARE) Network of the National Heart, Lung, and Blood Institute. Step-up therapy for children with uncontrolled asthma receiving inhaled corticosteroids. N Engl J Med 2010;18;362(11):975-985.

30. Thomas B, Rutman A, Hirst RA, Haldar P, Wardlaw AJ, Bankart J, et al. Ciliary dysfunction and ultrastructural abnormalities are features of severe asthma. J Allergy Clin Immunol 2010;126(4):722729.

31. Deshpande DA, Wang WC, McIlmoyle EL, Robinett KS, Schillinger RM, An SS, et al. Bitter taste receptors on airway smooth muscle bronchodilate by localized calcium signaling and reverse obstruction. Nat Med 2010;16(11):1299-1304.

32. Mannino DM, Buist AS. Global burden of COPD: risk factors, prevalence, and future trends. Lancet 2007;370(9589):765-773

33. Martinez FD. The origins of asthma and chronic obstructive pulmonary disease in early life. Proc Am Thorac Soc 2009;6(3):272277.

34. Svanes C, Sunyer J, Plana E, Dharmage S, Heinrich J, Jarvis D, et al. Early life origins of chronic obstructive pulmonary disease. Tho$\operatorname{rax} 2010 ; 65(1): 14-20$

35. Holick MF. Vitamin D deficiency. N Engl J Med 2007;357(3):266281.

36. Chapuy MC, Preziosi P, Maamer M, Arnaud S, Galan P, Hercberg S, Meunier PJ. Prevalence of Vitamin D insufficiency in an adult normal population. Osteoporos Int 1997;7(5):439-443.

37. Dawson-Hughes B, Heaney RP, Holick MF, Lips P, Meunier PJ, Vieth R. Estimates of optimal vitamin D status. Osteoporos Int 2005;16(7):713-716.

38. Black PN, Scragg R. Relationship between serum 25-hydroxyvitamin D and pulmonary function in the third national health and nutrition examination survey. Chest 2005;128(6):3792-3798.

39. Janssens W, Bouillon R, Claes B, Carremans C, Lehouck A, Buysschaert I, et al. Vitamin D deficiency is highly prevalent in COPD and correlates with variants in the Vitamin D-binding gene. Thorax 2010;65(3):215-220.

40. Sin DD, Man SF. Why are patients with chronic obstructive pulmonary disease at increased risk of cardiovascular diseases? The potential role of systemic inflammation in chronic obstructive pulmonary disease. Circulation 2003;107(11):1514-1519.

41. Hole DJ, Watt GC, Davey-Smith G, Hart CL, Gillis CR, Hawthorne VM. Impaired lung function and mortality risk in men and women: findings from the Renfrew and Paisley prospective population study. BMJ 1996;313(7059):711-716.

42. Smith Sc Jr., Allen J, Blair SN, Bonow RO, Brass LM, Fonarow GC, et al; AHA/ACC; National Heart, Lung, and Blood Institute. AHA/ACC guidelines for secondary prevention for patients with coronary and other atherosclerotic vascular disease 2006 update: endorsed by the National Heart, Lung and Blood Institute. Circulation 2006;113(19):2363-2372. Erratum in: Circulation 2006; 113(22):e847.

43. Hunt SA, Abraham WT, Chin MH, Feldman AM, Francis GS, Ganiats TG, et al; American College of Cardiology Foundation; American Heart Association. 2009 focused update incorporated into the ACC/AHA 2005 guidelines for the Diagnosis and Management of Heart Failure in Adults: a report of the American College of Cardiology Foundation/American Heart Association Task Force on Practice Guidelines developed in collaboration with the International Society for Heart and Lung Transplantation. J Am Coll Car- 


\section{Respiratory Care Year in Review 2010: Part 1}

diol 2009;53(15):e1-e90. Erratum in: J Am Coll Cardiol 2009; 54(25):2464

44. Egred M, Shaw S, Mohammad B, Waitt P, Rodrigues E. Under-use of beta-blockers in patients with ischemic heart disease and concomitant chronic obstructive pulmonary disease. QJM 2005;98(7): 493-497.

45. Rutten FH, Zuithoff NP, Hak E, Grobbee DE, Hoes AW. Betablockers may reduce mortality and risk of exacerbations in patients with chronic obstructive pulmonary disease. Arch Intern Med 2010; 170(10):880-887.

46. Thompson WH, Nielson CP, Carvalho P, Charan NB, Crowley JJ. Controlled trial of oral prednisone in outpatients with acute COPD exacerbation. Am J Respir Crit Care Med 1996;154(2 Pt 1):407412.

47. Niewoehner DE, Erbland ML, Deupree RH, Collins D, Gross NJ, Light RW, et al. Effect of systemic glucocorticoids on exacerbations of chronic obstructive pulmonary disease. N Engl J Med 1999;340(25):1941-1947.

48. Global Initiative for Chronic Obstructive Lung Disease (GOLD). Global strategy for the diagnosis, management and prevention of chronic obstructive pulmonary disease. Executive summary, updated 2009. http://www.goldcopd.org/guidelineitem.asp?11=2\& 12=1\&intid=2180. Accessed February 4, 2011.

49. National Collaborating Center for Chronic Conditions. Chronic obstructive pulmonary disease: national clinical guideline for management of chronic obstructive pulmonary disease in adults in primary and secondary care. Thorax 2004;59(Suppl 1):1-232.

50. Celli BR, MacNee W; ATS/ERS Task Force. Standards for the diagnosis and treatment of patients with COPD: a summary of the ATS/ERS position paper. Eur Respir J 2004;23(6):932-946.

51. Lindenauer PK, Pekow PS, Lahti MC, Lee Y, Benjamin EM, Rothberg MB. Association of corticosteroid dose and route of administration with risk of treatment failure in acute exacerbation of chronic obstructive pulmonary disease. JAMA 2010;303(23):2359-2367.

52. Sassoon CS, Hassell KT, Mahutte CK. Hyperoxic-induced hypercapnia in stable chronic obstructive pulmonary disease. Am Rev Respir Dis 1987;135(4):907-911.

53. Robinson TD, Freiberg DB, Regnis JA, Young IH. The role of hypoventilation and ventilation-perfusion redistribution in oxygeninduced hypercapnia during acute exacerbations of chronic obstructive pulmonary disease. Am J Respir Crit Care Med 2000;161(5): 1524-1529.

54. Denniston AK, O'Brien C, Stableforth D. The use of oxygen in acute exacerbations of chronic obstructive pulmonary disease: a prospective audit of pre-hospital and hospital emergency management. Clin Med 2002;2(5):449-451.

55. Plant PK, Owen JL, Elliott MW. One year period prevalence study of respiratory acidosis in acute exacerbations of COPD; implications for the provision of non-invasive ventilation and oxygen administration. Thorax 2000;55(7):550-554.

56. Wijesinghe M, Perrin K, Healy B, Hart K, Clay J, Weatherall M, Beasley R. Pre-hospital oxygen therapy in acute exacerbations of chronic obstructive pulmonary disease. Intern Med J 2010;[Epub ahead of print]

57. Austin MA, Willis KE, Blizzard L, Walters EH, Wood-Baker R. Effect of high flow oxygen on mortality in chronic obstructive pulmonary disease patients in prehospital setting: randomized controlled trial. BMJ 2010;341:c5462 DOI:10.1136/bmjc5462.

58. Almagro P, Salvadó M, Garcia-Vidal C, Rodriguez-Carballeira M, Delgado M, Barreiro B, et al. Recent improvement in long-term survival after a COPD hospitalization. Thorax 2010;65(4):298-302.

59. Borg BM, Hartley MF, Fisher MT, Thompson BR. Spirometry training does not guarantee valid results. Respir Care 2010;55(6): 689-694.
60. Masa JF, González MT, Pereira R, Mota M, Riesco JA, Corral J, et al. Validity of spirometry performed on-line. Eur Respir J 2010; [Epub ahead of print]

61. O'Donnell CR, Bankier AA, Stiebellehner L, Reilly JJ, Brown R, Loring SH. Comparison of plethysmographic and helium dilution lung volumes: which is best in COPD? Chest 2010;137(5):11081115 .

62. Stanojevic S, Wade A, Cole TJ, Lum S, Custovic A, Silverman M, et al; Asthma UK Spirometry Collaborative Group. Spirometry centile charts for young Caucasian children: the Asthma UK Collaborative Initiative. Am J Respir Crit Care Med 2009;180(6):547552.

63. Quanjer PH, Stocks J, Cole TJ, Hall GL, Stanojevic S; ERS Global Lungs Task Force. Influence of secular trends and sample size on reference equations for lung function tests. Eur Respir J 2010; [Epub ahead of print]

64. Hankinson JL, Kawut SM, Shahar E, Smith LJ, Stukovsky KH, Barr RG. Performance of American Thoracic Society-recommended reference values in a multiethnic sample of adults: the multi-ethnic study of atherosclerosis (MESA) lung study. Chest 2010;137(1): 138-145.

65. Miller MR, Pedersen OF. New concepts for expressing forced expiratory volume in $1 \mathrm{~s}$ arising from survival analysis. Eur Respir $\mathrm{J}$ 2010;35(4):873-882.

66. Quanjer PH, Stanojevic S, Stocks J, Hall GL, Prasad KV, Cole TJ, et al. Global Lungs Initiative. Changes in the $\mathrm{FEV}_{1} / \mathrm{FVC}$ ratio during childhood and adolescence: an intercontinental study. Eur Respir J 2010;36(6):1391-1399.

67. Hansen JE, Sun XG, Wasserman K. Calculating gambling odds and lung age for smokers. Eur Respir J 2010;35(4):776-780.

68. Newbury W, Newbury J, Briggs N, Crockett A. Exploring the need to update lung age equations. Prim Care Respir J 2010;19(3):242247.

69. Miller MR, Quanjer PH, Swanney MP, Ruppel G, Enright PL. Interpreting pulmonary function data using $80 \%$ predicted and fixed thresholds misclassifies over $20 \%$ of patients. Chest $2011 ; 139(1)$ : 52-59.

70. Vaz Fragoso CA, Concato J, McAvay G, Van Ness PH, Rochester $\mathrm{CL}$, Yaggi HK, Gill TM. The ratio of $\mathrm{FEV}_{1} / \mathrm{FVC}$ as a basis for establishing chronic obstructive pulmonary disease. Am J Respir Crit Care Med 2010;181(5):446-451.

71. Quanjer PH, Enright PL, Ruppel GL. The GOLD guidelines definition of mild airway obstruction (letter). Respir Care 2010;55(10): 1397-1398.

72. Kollef MH, Afessa B, Anzueto A, Veremakis C, Kerr KM, Margolis BD, et al; NASCENT Investigation Group. Silver-coated endotracheal tubes and incidence of ventilator-associated pneumonia: the NASCENT randomized trial. JAMA 2008;300(7):805-813.

73. Rello J, Afessa B, Anzueto A, Arroliga AC, Olson ME, Restrepo MI, et al. Activity of a silver-coated endotracheal tube in preclinical models of ventilator-associated pneumonia and a study after extubation. Crit Care Med 2010;38(4):1135-1140.

74. Afessa B, Shorr AF, Anzueto AR, Craven DE, Schinner R, Kollef $\mathrm{MH}$. Association between a silver-coated endotracheal tube and reduced mortality in patients with ventilator-associated pneumonia. Chest 2010;137(5):1015-1021.

75. Neiderman MS. Fighting vampires and ventilator-associated pneumonia: is silver the magic bullet? Chest 2010;137(5):1007-1009.

76. Palmore TN, Henderson DK. Testing the tube: assessing silver as a potential "silver bullet" for preventing ventilator-associated pneumonia. Crit Care Med 2010;38(4):1220-1221.

77. Deem S, Treggiari MM. New endotracheal tubes designed to prevent ventilator-associated pneumonia: do they make a difference? Respir Care 2010;55(8):1046-1055. 


\section{Respiratory Care Year in Review 2010: Part 1}

78. Gentile MA, Siobal MS. Are specialized endotracheal tubes and heat-and-moisture exchangers cost-effective in preventing ventilator associated pneumonia? Respir Care 2010;55(2):184-196.

79. Lacherade JC, De Jonghe B, Guezennec P, Debbat K, Hayon J, Monsel A, et al. Intermittent subglottic secretion drainage and ventilator-associated pneumonia: a multicenter trial. Am J Respir Crit Care Med 2010;182(7):910-917.

80. Terragni PP, Antonelli M, Fumagalli R, Faggiano C, Beradino M, Pallavicini FB, et al. Early vs. late tracheotomy for prevention of pneumonia in mechanically ventilated adult ICU patients: a randomized controlled trial. JAMA 2010;303(15):1483-1489.

81. Durbin CG Jr, Perkins MP, Moores LK. Should tracheostomy be performed as early as 72 hours in patients requiring prolonged mechanical ventilation? Respir Care 2010;55(1):76-87.

82. Pitts R, Fisher D, Sulemanji D, Kratohvil J, Jiang Y, Kacmarek R. Variables affecting leakage past endotracheal tube cuffs: a bench study. Intensive Care Med 2010;36(12):2066-2073.

83. Zanella A, Scaravilli V, Isgrò S, Milan M, Cressoni M, Patroniti N, et al. Fluid leakage across tracheal tube cuff, effect of different cuff material, shape, and positive expiratory pressure: a bench-top study. Intensive Care Med 2010; [Epub ahead of print]

84. Dave MH, Frotzler A, Spielmann N, Madjdpour C, Weiss M. Effect of tracheal tube cuff shape on fluid leakage across the cuff: an in vitro study. Br J Anaesth 2010;105(4):538-543.

85. Dave MH, Koepfer N, Madjdpour C, Frotzler A, Weiss M. Tracheal fluid leakage in benchtop trials: comparison of static versus dynamic ventilation model with and without lubrication. J Anesth 2010;24(2):247-252.

86. Burns KE, Adhikari NK, Keenan SP, Meade MO. Noninvasive positive pressure ventilation as a weaning strategy for intubated adults with respiratory failure. Cochrane Database Syst Rev 2010; (8):CD004127.

87. Kohlenberg A, Schwab F, Behnke M, Geffers C, Gastmeier P. Pneumonia associated with invasive and noninvasive ventilation: an analysis of the German nosocomial infection surveillance system database. Intensive Care Med 2010;36(6):971-978.

88. Maxwell RA, Green JM, Waldrop J, Dart BW, Smith PW, Brooks $\mathrm{D}$, et al. A randomized prospective trial of airway pressure release ventilation and low tidal volume ventilation in adult trauma patients with acute respiratory failure. J Trauma 2010;69(3):501-510.

89. Rello J, Chastre J, Cornaglia G, Masterton R; VAP Care Bundles Contributors. A European care bundle for management of ventilator-associated pneumonia. J Crit Care 2010; [Epub ahead of print].

90. Miller RS, Norris PR Jenkins JM, Talbot TR III, Starmer JM, Hutchison SA, et al. Systems initiatives reduce healthcare-associated infections: a study of 22,928 device days in a single trauma unit. J Trauma 2010;68(1):23-31.
91. Bouadma L, Deslandes E, Lolom I, Le Corre B, Mourvillier B, Regnier B, et al. Long-term impact of a multifaceted prevention program on ventilator-associated pneumonia in a medical intensive care unit. Clin Infect Dis 2010;51(10):1115-1122.

92. Magret M, Amaya-Villar R, Garnacho J, Lisboa T, Díaz E, Dewaele J, et al; EU-VAP/CAP Study Group. Ventilator-associated pneumonia in trauma patients is associated with lower mortality: results from EU-VAP study. J Trauma 2010;69(4):849-854.

93. Restrepo MI, Anzueto A, Arroliga AC, Afessa B, Atkinson MJ, Ho $\mathrm{NJ}$, et al. Economic burden of ventilator-associated pneumonia based on total resource utilization. Infect Control Hosp Epidemiol 2010; 31(5):509-515.

94. Czosnowski QA, Wood GC, Magnotti LJ, Croce MA, Swanson JM, Boucher BA, Fabian TC. Adjunctive aerosolized antibiotics for treatment of ventilator-associated pneumonia. Pharmacotherapy 2009;29(9):1054-1060.

95. Mounier R, Adrie C, Français A, Garrouste-Orgeas M, Cheval C, Allaouchiche B, et al; OUTCOMEREA Study Group. Study of prone positioning to reduce ventilator-associated pneumonia in hypoxaemic patients. Eur Respir J 2010;35(4):795-804.

96. Staudinger T, Bojic A, Holzinger U, Meyer B, Rohwer M, Maliner $\mathrm{F}$, et al. Continuous lateral rotation therapy to prevent ventilatorassociated pneumonia. Crit Care Med 2010;38(2):486-490.

97. Mauri T, Berra L, Kumwilaisak K, Pivi S, Ufberg JW, Kueppers F, et al. Lateral-horizontal patient position and horizontal orientation of the endotracheal tube to prevent aspiration in adult surgical intensive care unit patients: a feasibility study. Respir Care 2010; 55(3):294-302.

98. Morrow LE, Kollef MH, Casale TB. Probiotic prophylaxis of ventilator-associated pneumonia: a blinded, randomized, controlled trial. Am J Respir Crit Care Med 2010;182(8):1058-1064.

99. Barraud D, Blard C, Hein F, Marçon O, Cravoisy A, Nace L, et al. Probiotics in the critically ill patient: a double blind, randomized, placebo-controlled trial. Intensive Care Med 2010;36(9):1540-1547.

100. Siempos II, Ntaidou TK, Falagas ME. Impact of the administration of probiotics on the incidence of ventilator-associated pneumonia: a meta-analysis of randomized controlled. Crit Care Med 2010; 38(3):954-962.

101. Han J, Liu Y. Effect of ventilator circuit changes on ventilatorassociated pneumonia: a systematic review and meta-analysis. Respir Care 2010;55(4):467-474.

102. Samransamruajkit R, Jirapaiboonsuk S, Siritantiwat S, Tungsrijitdee O, Deerojanawong J, Sritippayawan S, Prapphal N. Effect of frequency of ventilator circuit changes ( 3 vs 7 days) on the rate of ventilator-associated pneumonia in PICU. J Crit Care 2010;25(1): $56-61$. 